\title{
Por um estatuto epistemológico da análise do discurso ${ }^{1}$
}

\author{
Rogério Christofoletti \\ Universidade Federal de Santa Catarina
}

\section{Abstract}

This article aims to bring some contributions to the discussion of the epistemological status of French Discourse Analysis. Because there isn't a single answer to this question yet, this work will study several authors and their observations about the French Discourse Analysis and its epistemologicals limits. 
"Porém, ela não é lingüística tampouco. Precisamente porque ela é ampla, conflituosa, é marcada como nãolingüística e recolocada por alguns lingüistas a este ponto de onde ela se vê afastar: o Poder, a Instituição."

(J. Sumpf)

\section{INTRODUÇÃO}

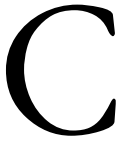

om quase trinta anos do surgimento de seu texto-fundador - AAD-69 - a escola francesa da Análise do Discurso ainda se ressente de não ter um estatuto epistemológico homogêneo entre seus pesquisadores. É ela uma disciplina da Lingüística? Apenas método de interpretação? Uma transdisciplina lingüística que tangencia também a História, a Psicologia e outros campos? Como resolver essa questão que parece tão fundamental para um terreno teórico que reivindica sua especificidade?

A concepção de Maingueneau (1989:17) acerca da relação delicada entre a Análise de Discurso (doravante AD) e a Lingüística estimula este trabalho a lançar algumas notas acerca dos limites epistemológicos da AD. É através dos caminhos que Maingueneau aponta que revisitaremos algumas das hipóteses sobre o estatuto epistemológico da AD. Nesse (per)(dis)curso, colocaremos algumas noções em linha de confronto, buscando respostas e tentando contribuir de alguma maneira para a questão.

\section{DENTRO OU FORA - DENTRO E FORA}

Dominique Maingueneau (1989:9) afirma que o lugar da AD, quando de seu aparecimento, "não estava previamente inscrito no 
campo do saber" e, por essa razão, é melhor interpretá-la "no interior de uma certa tradição, como o encontro de uma conjuntura intelectual e de uma prática escolar". Dessa forma, a escola francesa de Análise do Discurso teria nascido sob o signo do estruturalismo e da explicação de textos, prática habitual naquele país. Entretanto, tal distinção - essa reclassificação cuidadosa da AD como campo de conhecimento - apenas dá uma amostra de quão tensa é a situação epistemológica desta corrente de estudo que partiu da Europa e hoje tem adeptos, por exemplo, no Brasil.

Se, por um lado, o surgimento da AD não estivesse dentro das linhas que delimitam o campo do saber, por outro, hoje, a AD alargou seus tentáculos e ampliou seu raio de alcance. O número de pesquisadores e de trabalhos de análise também cresceu, além, é claro, da necessidade de se aprofundar no estudo do estatuto próprio da AD. Nunca é demais lembrar que no começo de sua história, a análise proposta por Michel Pêcheux se colocava como um dispositivo experimental (cf. Henry, 1990:25). Atualmente, sob a marca AD não se tem tão unicamente uma metodologia de leitura/interpretação. Dessa forma, como a AD dos nossos dias é bem diferente da de outrora, é necessário reconsiderar o que significa este corpo teóricometodológico, determinar sua relação com a Lingüística, enquanto ciência da língua, e estabelecer algumas bases para que se orientem os próximos desenvolvimentos da AD.

Voltando a Maingueneau, que também tinha essa preocupação (1989:13, 188), temos um esboço de como estaria assentada a AD em parentesco com a Lingüística: haveria duas zonas de campo, uma dedicada ao estudo da língua e outra voltada à linguagem. Os limites que separariam as duas instâncias não seriam demarcados, fato que só dificulta a visibilidade de um domínio específico da AD, que estaria transitando entre a língua e a linguagem. Para matizar mais a questão, Courtine (apud Maingueneau, 1989:17) afirma ainda que na $\mathrm{AD}$, "é preciso ser lingüista e deixar de sê-lo ao mesmo tempo", de forma a mostrar que a discursividade tem uma ordem diferente da materialidade lingüística, mas que, em compensação, se efetiva 
na língua. Essa situação, para Maingueneau "tanto impede a AD de deixar o campo lingüístico, quanto de se enclausurar nesta ou naquela de suas escolas ou ramos" (17-18). Com isso, Maingueneau conclui que a $\mathrm{AD}$ não é uma parte da Lingüística a exemplo de outras disciplinas, como a lexicologia. Mas atravessa os diversos outros braços da Lingüística.

Já aqui, pode-se observar pelo menos duas concepções ligeiramente distintas acerca do estatuto epistemológico da AD: uma que acredita na constitucionalidade lingüística, o que tornaria a AD uma espécie de disciplina da Lingüística e outra concepção que vê na $\mathrm{AD}$ um campo interdisciplinar lingüístico. A primeira noção se fundamenta no fato de os analistas do discurso trabalharem também sobre a superfície lingüística dos enunciados. Com isso, ao lidar com a língua, sua linha de pesquisa estabeleceria ligações estreitas com a Lingüística. No afã de se buscar um estatuto para a AD, tem-se de imediato que ela é uma disciplina lingüística, a exemplo da morfologia, da fonética ou da sintaxe. Dubois et al. (1978:50), por exemplo, classificam a AD dessa forma.

A segunda noção - a da interdisciplinaridade - tem como base a singularidade da $\mathrm{AD}$ em não tão somente trabalhar no campo da língua, mas também nos limites das ciências humanas e sociais. Branca-Rosoff et al. lembram que "saber lingüístico e saber social se reencontram na descrição mesma do discurso, facilitando assim a interface [do analista do discurso/lingüista] com o historiador e o sociólogo" (1995:64). No nível da própria Lingüística, a AD também seria interdisciplinar, já que passa por outros domínios, como o da semântica.

Entretanto, essas primeiras concepções epistemológicas não satisfazem a singularidade de ser da AD. Pensar simplesmente que a AD se limita a uma disciplina lingüística é desconhecer seu alcance para além das fronteiras da Lingüística e ignorar o próprio conceito de discurso, ${ }^{2}$ como fato social e como estrutura de linguagem. A AD não é só e tão somente uma parte da Lingüística porque, entre outras razões, é quase impossível se observar sua limitação nesse campo. 
Os conceitos que a $\mathrm{AD}$ traz do materialismo histórico, da psicanálise lacaniana e de uma teoria das ideologias, entre outros, não são de ordem lingüística. São de outra natureza.

Por outro lado, tomar esse dado e fixar a AD como uma abordagem interdisciplinar é também uma atitude extremada, pois isso fragiliza a constituição específica da AD. Orlandi (1996: 24) aponta que "a interdisciplinaridade dá idéia de instrumentalização de uma disciplina pela outra (ainda que na bi-direcionalidade)". Dessa forma, Orlandi imputa à AD uma condição de "desdisciplina" ou "disciplina de entremeio", isto é, a AD não se faz na medida em que instrumentaliza as outras ciências de que faz uso, mas sua constituição se dá na contradição dessas disciplinas:

"A AD produz um outro lugar de conhecimento com sua especificidade. Não é mera aplicação da lingüística sobre as ciências sociais e vice-versa. A AD se forma no lugar em que a linguagem tem de ser referida necessariamente à sua exterioridade, para que se apreenda seu funcionamento, enquanto processo significativo." (1996:24)

Robin, por sua vez, também critica a tendência de se colocar a AD entre a Lingüística e as ciências humanas. Tentar crer que a AD é uma ponte entre o terreno lingüístico e os demais não passa de um "mal-entendido":

\footnotetext{
"Sem ecumenismo nem ecletismo, [a $\mathrm{AD}$ ] não se professa nem disciplina auxiliar, nem campo autônomo. Ela lembra nessa sua tenacidade, no interior da problemática mesma de cada disciplina, que o registro da língua é irredutível a um conjunto de atos, ou de práticas sociais, ou mesmo redutível a uma máquina lógicosemântica". (1986:127)
}

Ainda de acordo com Robin, se antes a AD ainda tematizava o objeto discursivo como objeto teórico, hoje, ela já não se pode se prender a um objeto fronteiriço. A AD atua nos "limites dos grandes recortes disciplinares, constituindo-se por cada um dos dois dentro/ fora, de forma inquieta”, conclui. 
Entretanto, apesar de Robin e Orlandi rechaçarem os estatutos de interdisciplinaridade e de intermediação, trabalhar sob as idéias de que a $\mathrm{AD}$ se forme na contradição de outras disciplinas ou de que ela esteja no limite dos recortes disciplinares é, de forma velada (e talvez inconsciente), aceitar uma condição de "auxiliaridade". Isto é, ainda persiste uma relação de dependência da AD junto a outras disciplinas no processo de constituição de seu campo específico. Considerar a AD como uma perspectiva que se faz na contradição da Lingüística e das ciências sociais é sustentável, mas ao mesmo tempo subestima um esforço de autoconstituição que a AD realizou até então. ${ }^{3}$ É fato que a AD trouxe, na época de seu surgimento, conceitos de outros segmentos científicos. Naquele momento (1969), sim, a AD era um campo interdisciplinar, porque colhia idéias daqui e de lá. Entretanto, como toda abordagem, a AD sofreu modificações, amadureceu e aprofundou questões. Não se pode pensar esses dois momentos - o inicial e o atual - como os mesmos, porque eles não o são. Mas mesmo o fato de que alguns conceitos tenham sido contrabandeados para um espaço teórico que iria se tornar a AD, no instante em que essas noções se viram neste novo território, relacionando-se mutuamente, deixaram de ser estritamente aqueles conceitos emprestados da psicanálise, do marxismo, etc., porque se alteraram, se adequaram a um corpo teórico composto de outros tantos conceitos.

Persistindo no raciocínio, observamos ainda que considerar o espaço da AD no "dentro/fora, de forma inquieta” é não assegurar nenhum lugar para ela. A imagem que Robin constrói é efetivamente eficaz no que concerne trazer movimento e dinamismo à ação da $\mathrm{AD}$ entre a Lingüística e as ciências humanas, mas creio que é insuficiente para resolver a pergunta deste trabalho que refaço agora de outra forma: qual é o lugar da Análise do Discurso? 


\title{
A NATUREZA DO OBJETO E DA PRÁTICA
}

É preciso pensar a AD como conhecimento autônomo, da mesma forma que se pensa a psicanálise, que é uma forma específica de conhecimento. O fato de a AD ter como objeto de estudo o discurso e tocar uma série de campos independentes não faz dela uma interdisciplina, nem sequer uma disciplina auxiliar (meramente um dispositivo de interpretação a mais para a Lingüística). Mas alguém há de perguntar: a AD está ou não está na Lingüística? Estar em contato com não significa necessariamente estar contido em. Dessa forma, a AD, evidentemente, trabalha com a Lingüística, bem assim como lida com as ciências humanas e sequer ela é classificada no rol das humanidades. Essa característica singular - que permite transitar entre esses módulos teóricos - se deve à própria natureza do objeto de análise da AD: o discurso.

Para Branca-Rosoff,

\begin{abstract}
"a especificidade da AD nas ciências humanas repousa sobre a incontornável presença da materialidade da linguagem no seio do processo social: ela transforma em efeito seu próprio objeto a partir dos recursos da linguagem, de sua dimensão funcional reflexiva. Ela é uma disciplina interpretativa, irredutível a todo formalismo lingüístico assim como a toda leitura não-instrumentalizada.” (1995:54)
\end{abstract}

Orlandi (1986:62) lembra que "a noção de discurso desloca a reflexão para além da dicotomia língua/fala ou competência/ desempenho". Dessa forma, a língua não surge como "sistema abstrato (ideologicamente neutro) ou como código (com função puramente informativa)". Orlandi afirma ainda que ocorre a recusa da noção de competência, "já que esta supõe que os locutores, que em Chomsky são ideais, não têm nem história nem inconsciente". Mas não só isso. O conceito de discurso perpassa uma infinidade de lugares, ganhando força e absorvendo significação. No interior dessa passagem contínua que realiza, o discurso não se coloca como estrutura exclusivamente lingüística ou histórica, nem tampouco 
filosófica ou ideológica. Assim, o discurso não "pertence" à Lingüística, assim como os números estão para a Matemática ou os elementos químicos estão para a Química. O discurso não se prende a uma disciplina, mas pode se servir como objeto de análise de corpos teóricos como a AD. ${ }^{4}$ Essa singularidade do discurso é reabsorvida pela $\mathrm{AD}$ na prática cotidiana de análise; o objeto de estudo em questão dita as regras de comportamento ao pesquisador, obrigando-o a se adequar a uma certa condição de instabilidade e dinamismo.

Mas o desconforto da condição da AD, que dificulta sua classificação nas ciências, também é conseqüência de sua natureza enquanto prática analítica, interpretativa. Pêcheux (1990: 51) contribui para a questão:

"O objeto da lingüística (o próprio da língua) aparece assim atravessado por uma divisão discursiva entre dois espaços: o da manipulação de significações estabilizadas, normatizadas por uma higiene pedagógica do pensamento, e o de transformações do sentido, escapando a qualquer norma estabelecida a priori, de um trabalho do sentido sobre o sentido, tomados no relançar indefinido das interpretações."

Não é à toa que o próprio Pêcheux questiona a natureza do discurso, indagando ser ele estrutura ou acontecimento. Mesmo porque a preocupação é o analista do discurso trazer alguns traços do acontecimento histórico para dentro da interpretação, fato que privilegiaria a aceitação de um "transcendental histórico, grade de leitura ou memória antecipadora do discurso" (cf. p. 56), o que pode contaminar a interpretação.

\section{À GUISA DE CONCLUSÃO...}

Mas se a $\mathrm{AD}$ não é uma parte da Lingüística nem sequer é uma ponte interdisciplinar entre o campo da língua e o das ciências humanas, ela é o que afinal? A exemplo da Tradução e da Crítica Literária, a AD também tem uma condição difícil de ser classificada. 
É por essa razão que nunca é demais discutir a questão e rever conceitos e limites.

Por trazer questões à Lingüística (a própria inserção da noção de discurso é um exemplo que contribui para o avanço das pesquisas na língua/linguagem), por se colocar também como um dispositivo de interpretação e leitura, e por retrabalhar outras noções lingüísticas (como a polifonia, por exemplo), a AD se constitui num Exercício Crítico da Linguagem. Isto é, a AD é um conjunto teórico que revitaliza as discussões de língua/linguagem, rearticulando contradições, desestruturando dicotomias que não se aplicam e trazendo ao estudo da linguagem conteúdos que, apesar de não serem exclusivos da Lingüística, também lhe são próprios e condizentes.

A AD parece ter uma certa autonomia enquanto campo de conhecimento, já que apresenta interfaces que lhe dão especificidade. A exemplo da Psicanálise, ela dispõe de um método interpretativo, de um arsenal teórico e de uma prática. Essas mesmas interfaces conferem à AD uma carga de ação crítica $^{5}$ que lhe transborda o simples papel de um modelo lingüístico, ou de qualquer outra natureza. No dispositivo de interpretação, o analista não apenas lê seu objeto, mas também recria seu objeto (o preenche de efeitos de sentido) à medida que realiza seu gesto de leitura em consonância com outros pressupostos teóricos da AD. ${ }^{6}$ Obviamente, tal atitude faz parte de um comportamento, de uma prática crítica, já que não é reprodutora maquinal de efeitos de sentido. Por esse viés não se pode pensar a AD como modelo também. Até porque, como é possível modelar um objeto (o discurso), cuja característica mais regular é a irregularidade? Dessa forma, a AD não é modelo.

Se de um lado assinto ao que Orlandi (1996:107) diz acerca da $\mathrm{AD}$ (ela "se pretende uma teoria crítica da linguagem"), de outro, discordo que isso venha a ser um "sintoma de uma crise interna da Lingüística”. A expressão Exercício Crítico da Linguagem, que uso neste trabalho, traz em seu bojo um pouco do conceito formulado por Horkheimer (1991:44-46): ao se referir à sua Teoria Crítica: uma Teoria Crítica pretende que os homens protestem contra a aceitação resignada da ordem totalitária. A AD dialoga aqui com o conceito 
alemão, já que também em sua prática não impõe uma única leitura - a óbvia, a aparente... -, mas implode essa grade, propondo novos efeitos de sentido. Mas se a AD não se posiciona como uma "impositura", obrigando leituras, também não se permite ela mesma uma impostura, um embuste qualquer que admita qualquer tipo de leitura. Mesmo porque a AD não se coloca como prática crítica apenas e tão somente da Lingüística, mas também do próprio processo de estabelecimento do discurso em sua gramática, em seu funcionamento.

\section{NOTAS}

${ }^{1}$ Uma primeira versão deste artigo foi apresentada no Simpósio Internacional sobre Análise do Discurso: Controvérsias e Perspectivas, em Belo Horizonte (MG), em novembro de 1997.

${ }^{2}$ Aqui me remeto principalmente às discussões de Michel Foucault em seu $A$ arqueologia do saber, onde o filósofo trilha demorada e pacientemente um percurso de circunscrição da noção de discurso, através das concepções de enunciado e formação discursiva. A remissão vale também para o verbete discurso que J. Dubois et al. apresentam em seu Dicionário de Lingüística.

${ }^{3}$ Refiro-me a toda produção dos analistas de discurso até hoje. De $A A D-69 \mathrm{em}$ diante, a Análise do Discurso reviu percursos de abordagem de corpus, aperfeiçoou sua metodologia, e intensificou a reflexão sobre sua própria condição. Sem dúvida, tudo isso evidencia um exercício de busca de uma identidade própria da $\mathrm{AD}$, mesmo que os responsáveis não se dêem conta disso.

${ }^{4} \mathrm{Na}$ França, por exemplo, a $\mathrm{AD}$ atraiu o interesse não apenas de lingüistas, como parece ser o caso brasileiro, mas também de historiadores e de filósofos.

${ }^{5}$ Por essa razão, não considero adequada a terminologia Análise Crítica do Discurso, dada aos estudos analíticos vindos de uma tradição anglo-saxônica. O uso desta nomenclatura, por contraste, facilita o entendimento de que a Análise do Discurso de linha francesa seja destituída de senso crítico, o que não se verifica.

${ }^{6}$ Uma metáfora que auxiliaria no entendimento deste processo é a do caleidoscópio: quando se olha pelo visor, têm-se as mais variadas formas, e quem as observa compõe as configurações no momento em que gira o instrumento, refazendo operações sucessivas, recondicionando as partículas de papel colorido. O jogo de espelhos, interno ao caleidoscópio, evidentemente, amplia as possibilidades de leitura, mas também causa ilusões, com as quais o analista do discurso também pode se deixar seduzir. 


\section{REFERÊNCIAS BIBLIOGRÁFICAS}

BRANCA-ROSOFF, S. et al. Questions d'histoire et de sens. Langages, no 117, p. 54-66. 1995.

DUBOIS, J. et al. Dicionário de Lingüística. São Paulo: Cultrix, 1978.

FOUCAULT, M. A arqueologia do saber. Rio de Janeiro: Forense-Universitária, 1986.

HENRY, P. Os fundamentos teóricos da "Análise Automática do Discurso" de Michel Pêcheux . In: GADET, F. \& HAK, T. (Org. ${ }^{\text {) }}$ Por uma análise automática do discurso. Campinas: Ed. da Unicamp, 1990.

HORKHEIMER, M. Teoria Tradicional e Teoria Crítica. In: Adorno-Horkbeimer, Col. Os Pensadores. São Paulo: Nova Cultural, 1991.

MAINGUENEAU, D. Novas tendências em Análise do Discurso. Campinas: Pontes, 1989.

ORLANDI, E.P. Interpretação. Petrópolis: Vozes, 1996.

ORLANDI, E.P. O que é lingüística. São Paulo: Brasiliense, 1986.

PÊCHEUX, M. O discurso: estrutura ou acontecimento? Campinas: Pontes, 1990.

ROBIN, R. L'Analyse du Discours entre la linguistique et les sciences humaines: l'éternel malentendu. Langages 81, p: 121-127, 1986. 